\title{
Characteristics and treatment of geriatric patients in an osteopathic neuromusculoskeletal medicine clinic
}

https://doi.org/10.1515/jom-2020-0220

Received August 24, 2020; accepted November 19, 2020; published online February 19, 2021

\section{Abstract}

Context: Osteopathic manipulative medicine (OMM) is an adjunctive treatment approach available to geriatric patients, but few studies provide details about presenting conditions, treatments, and response to osteopathic manipulative treatment (OMT) in that patient population.

Objectives: To provide descriptive data on the presentation and management of geriatric patients receiving OMT at an outpatient osteopathic neuromusculoskeletal medicine (ONMM) clinic.

Methods: Data were retrospectively collected from electronic health records (EHR) at a single outpatient clinic for clinical encounters with patients over 60 years of age who were treated with OMT between July 1, 2016, and June 30, 2019. Records were reviewed for demographic information, insurance type, presenting concerns, assessments, regions treated, OMT techniques used, and treatment response.

Results: There were 9,155 total clinical encounters with 1,238 unique patients found during the study period. More women than men were represented for overall encounters $(6,910[75.4 \%]$ vs. 2,254 [24.6\%]) and unique patients (850 [68.7\%] vs. 388 [31.3\%]; both $\mathrm{p}<0.001$ ). The mean (standard deviation, SD) number of encounters per patient per year was 4.5 (4.0) and increased with increasing age by decade $(p<0.001)$. Medicare was the most common

*Corresponding author: Karen T. Snider, DO, Department of Family Medicine, Preventive Medicine, and Community Health, Kirksville College of Osteopathic Medicine, A.T. Still University, 800 W Jefferson St, Kirksville, MO 63501-1443, USA, E-mail: ksnider@atsu.edu Alicia A. King, DO, MPH, Private practice, Sikeston, MO, USA Jayme Cox, BS, OMS III, Kirksville College of Osteopathic Medicine, A.T. Still University, Kirksville, MO, USA

Shalini Bhatia, MS, Department of Research Support, A.T. Still University, Kirksville, MO, USA primary insurance $(7,246[79.2 \%])$, with private insurance the most common secondary insurance $(8,440[92.2 \%])$. The total number of presenting concerns was 12,020, and back concerns were most common $(6,406$ [53.3\%]). The total number of assessments was 18,290; most were neuromusculoskeletal $(17,271$ [94.5\%]) and in the thoracolumbar region (7,109 [38.9\%]). The mean (SD) number of somatic dysfunction assessments per encounter was 5 (1.7); the thoracic region was the most documented and treated $(7,263[15.8 \%])$. With up to 19 technique types per encounter, the total number of OMT techniques documented across all encounters was 43,862, and muscle energy $(7,203[16.4 \%])$ was the most documented. The use of high-velocity, low-amplitude (HVLA) declined as age increased $(\mathrm{p}<0.001)$. The overall treatment response was documented in 7,316 (79.9\%) encounters, and most indicated improvement $(7,290$ [99.6\%]).

Conclusions: Our results showed that geriatric patients receiving OMT at our clinic were predominately presenting for neuromusculoskeletal concerns associated with back, neck, and extremity conditions, consistent with national epidemiological data for this population. The most common OMT techniques were also consistent with those used nationally by osteopathic medical students and practicing physicians. Future longitudinal studies are needed to determine the length of time improvement persists and the overall health impact experienced by geriatric patients receiving OMT.

Keywords: geriatric patients; OMM; OMT; osteopathic manipulative medicine.

Osteopathic manipulative treatment (OMT) is the manual treatment aspect of osteopathic manipulative medicine (OMM) and is used by osteopathic physicians to improve structure-function relationships and promote the self regulatory and self healing capability of patients. It is also one of many adjunctive approaches accessed by geriatric patients [1-3]. Further, OMT can be used to treat somatic dysfunction associated with a wide range of 
musculoskeletal conditions in older patients, such as postural dysfunction, neck, and back pain, as well as non-musculoskeletal conditions such as constipation, pneumonia, and Parkinson disease [4-13]. For instance, in a previous study [14] of 21 nursing home residents aged 74 years and older, twice monthly OMT resulted in significantly reduced hospitalizations $(\mathrm{p}=0.04)$ and medication usage $(\mathrm{p}=0.02)$. In another study [10] of 406 hospitalized patients aged 50 years and older with pneumonia, twice-daily OMT was associated with significantly reduced length of stay $(\mathrm{p}=0.01)$ and reduced in-hospital mortality rates $(\mathrm{p}=0.008)$. In conjunction with other manual therapies, OMT has been shown to improve psychological symptoms in geriatric patients by decreasing anxiety and anxiety-associated physical signs, such as elevated heart rate, respiratory rate, and blood pressure $[8,11,15-18]$. Likely because of symptom improvement, OMT and similar manual therapies have been shown to improve quality of life in elderly patients [6, 19-21].

Currently, the clinical indication for OMT is the presence of somatic dysfunction found during physical examination [22]. However, there is a need to better define the types of clinical conditions that prompt evaluation for somatic dysfunction and that may benefit from the use of OMT as part of the treatment plan. Therefore, we need to determine the presenting concerns of geriatric patients who are treated with OMM, the types of conditions that include OMM as part of patient management, and the OMT techniques used. A 2016 study of 197 osteopathic neuromusculoskeletal medicine (ONMM) specialists by Channell et al. [1] showed that OMM was used in all geriatric age groups as part of the management of musculoskeletal concerns and conditions. Although many types of OMT techniques were used in geriatric patients in that study, high-velocity, low-amplitude (HVLA) was used much less frequently in patients aged 65 years and older [1]. To our knowledge, no other studies with similar descriptive data exist.

Therefore, the purpose of the current study was to provide descriptive data on the presentation and management of geriatric patients receiving OMT at an outpatient ONMM clinic. We hypothesized that most geriatric patients would present with musculoskeletal concerns, such as back and neck concerns, and be treated with a variety of OMT techniques. Specific data regarding the current use of OMM in the treatment of geriatric patients may be beneficial to guide patient care decisions on when to integrate OMM into the treatment plan. Results of the current study may also identify clinical conditions to target in future outcome studies focusing on quality of life, pain management, and fall risk reduction; the results may also suggest areas for improved training, effectiveness, and establishment of guidelines for OMM in the geriatric population.

\section{Methods}

This study was deemed exempt by the institutional review board at A.T. Still University-Kirksville. Informed consent was not obtained for this retrospective chart review. This study had no grant or funding support.

For this study, we employed a retrospective, observational design. Electronic health records (EHR) of an ONMM specialty clinic were reviewed for outpatient geriatric clinical encounters involving patients aged 60 years and older treated with OMT between July 1 , 2016, and June 30, 2019. The data was reviewed and analyzed by all authors between August 2019 and June 2020. We selected 60 years as the age cutoff instead of 65 years (when people become Medicare eligible in the United States) so we could compare decade cohorts and capture data from this transition period. Encounters of all geriatric patients seen by an attending physician, or a resident physician under the supervision of an attending physician, were included in the study. Participating physicians included seven attending physicians (including K.T.S.) and 17 resident physicians (including A.A.K.). The attending physicians were board certified or board eligible in NMM/ OMM. The resident physicians included eight NMM/OMM residents, five family medicine/NMM residents, two internal medicine/NMM residents, and two family medicine residents (including A.A.K).

The data were obtained from the clinic's EHR, NextGen Ambulatory EHR (Nextgen Healthcare Information Systems, Inc.). The query produced data files for demographic characteristics, presenting concerns, clinical assessments, and treatment information. The data were deidentified by removing the patient medical record number from the clinical encounter data before analysis and entered into a Microsoft Excel spreadsheet for tabulation and summary statistics. The demographic characteristics collected were age, sex, number of encounters per unique patient, and insurance type. Patient age was grouped by decade as 60-69, 70-79, 80-89, and 90 years and older. Primary and secondary insurance type were categorized as Medicaid, Medicare, private, or self-pay. The treatment information included the body regions of somatic dysfunction treated, OMT techniques used during the encounter, and the overall response to treatment. The 10 somatic dysfunction body regions included head, cervical, thoracic, lumbar, sacral, pelvic, lower extremity, upper extremity, rib, and abdomen. The EHR allowed 19 different types of OMT techniques to be documented. The OMT techniques used were recorded for each of the 10 body regions separately, but were counted only once per clinical encounter for the purposes of data analysis. Data from free-text narratives were excluded from the study.

Presenting concerns were grouped into neuromusculoskeletal or non-neuromusculoskeletal concerns. Neuromusculoskeletal concerns were then subclassified by body region, which included head, neck, thoracolumbar, hip/pelvis, lower extremity, upper extremity, rib/chest, abdomen, and nonspecific/generalized. These clinical assessments were grouped by International Classification of Diseases, Tenth Revision (ICD-10) category, body region, and clinical similarity as determined by three authors (K.T.S., A.A.K., J.C.) [23]. The assessments were categorized as neuromusculoskeletal and non-neuromusculoskeletal, and non-neuromusculoskeletal assessments were then subclassified by organ system. When the overall treatment response was documented, it was categorized as improved, unchanged, resolved, or worse.

Descriptive data were summarized using frequency and percentage for all encounters and for unique patients by age group. Mean and standard deviation (SD) values were calculated for 
encounters per year by age and sex, somatic dysfunction per encounter by age, and number of different types of OMT techniques per encounter. A binomial test of proportions was used to compare proportions between groups. A two-sample t test was used to compare mean encounters per year between women and men. Mean encounters per year were calculated over the three years of the study. An analysis of variance was used to compare mean number of somatic dysfunctions per encounter among age groups. Tukey's adjustment to the $p$ value was performed to control for type I error inflation due to multiple comparisons. A $\chi^{2}$ test of proportions was performed to determine whether the proportion of patient encounters using HVLA decreased by age group. All analyses were conducted using SAS version 9.4 (SAS Inc., Cary, NC). A value of $\mathrm{p}<0.05$ was considered statistically significant.

\section{Results}

The EHR query identified 9,155 clinical encounters with 1,238 geriatric patients during the study period (Table 1). By age group, there were 3,674 (40.1\%) encounters for patients aged 60-69 years, 3,213 (35.1\%) for those aged 70-79 years, 1,845 (20.2\%) for those aged 80-89 years, and 423 (4.6\%) for those aged 90 years and older. The number of unique patients was 609 (49.2\%) for those aged 60-69 years, 403 (32.6\%) for those aged 70-79 years, 190 (15.4\%) for those aged 80-89 years, and 36 (2.9\%) for those aged 90 years and older. Women had a larger number of encounters than men (6,901 [75.4\%] vs. $2,254$ [24.6\%], respectively; $\mathrm{p}<0.001)$ and represented more

Table 1: Demographic characteristics of geriatric patients from an outpatient osteopathic neuromusculoskeletal medicine clinic.

\begin{tabular}{|c|c|c|c|c|}
\hline \multirow[t]{2}{*}{ Characteristic } & \multicolumn{4}{|c|}{ Age group } \\
\hline & $\begin{array}{r}60-69 \\
\text { years }\end{array}$ & $\begin{array}{r}70-79 \\
\text { years }\end{array}$ & $\begin{array}{r}80-89 \\
\text { years }\end{array}$ & $\geq 90$ years \\
\hline \multicolumn{5}{|c|}{$\begin{array}{l}\text { Encounters } \\
(\mathrm{N}=9,155),{ }^{\mathrm{a}} \mathrm{n}(\%)\end{array}$} \\
\hline Total & $3,674(40.1)$ & $3,213(35.1)$ & $1,845(20.2)$ & $423(4.6)$ \\
\hline Women & $2,722(74.1)$ & $2,459(76.5)$ & $1,374(74.5)$ & $346(81.8)$ \\
\hline Men & $952(25.9)$ & $754(23.5)$ & $471(25.5)$ & $77(18.2)$ \\
\hline \multicolumn{5}{|c|}{ Patients $(\mathrm{N}=1,238),{ }^{\mathrm{b}} \mathrm{n}(\%)$} \\
\hline Total & $609(49.2)$ & $403(32.6)$ & $190(15.4)$ & $36(2.9)$ \\
\hline Women & $404(66.3)$ & $281(69.7)$ & $139(73.2)$ & $26(72.2)$ \\
\hline Men & $205(33.7)$ & $122(30.3)$ & $51(26.8)$ & $10(27.8)$ \\
\hline \multicolumn{5}{|c|}{ Encounters per patient per year, ${ }^{c}$ mean (SD) } \\
\hline Total & $4.2(4.3)$ & $4.4(3.4)$ & $5.4(4.2)$ & $5.6(4.1)$ \\
\hline Women & $4.6(4.7)$ & $4.6(3.4)$ & $5.4(4.0)$ & $6.3(4.3)$ \\
\hline Men & $3.5(3.1)$ & $3.8(3.3)$ & $5.2(4.9)$ & $3.7(2.8)$ \\
\hline
\end{tabular}

${ }^{\mathrm{a}}$ There were 6,901 (75.4\%) encounters with women and 2,254 (24.6\%) with men. ${ }^{\mathrm{b}}$ There were $850(68.7 \%)$ women patients and 388 (31.3\%) men. ${ }^{\mathrm{C}}$ Mean (standard deviation, SD) encounters per patient averaged over the three years of the study was 7.4 (9.1); mean (SD) number of encounters per patient per year was 4.5 (4.0). unique patients (850 [68.7\%] vs. 388 [31.3\%], respectively; $\mathrm{p}<0.001)$. The mean (SD) number of encounters per year by age group was 4.2 (4.3) for those aged 60-69 years, 4.4 (3.4) for those aged 70-79 years, 5.4 (4.2) for those aged 80-89 years, and 5.6 (4.1) for those aged 90 years and older. The number of encounters per year increased with age $(\mathrm{p}<0.001)$, and the mean (SD) number of encounters per year for women was larger than for men (4.8 [4.2] vs. 3.8 [3.5], respectively; $\mathrm{p}<0.001)$.

The primary insurance types for patients were Medicare $(7,246[79.2 \%])$, private insurance $(1,770$ [19.3\%]), self-pay (108 [1.2\%]), and Medicaid (31 [0.3\%]). Secondary insurance types were private insurance (8,440 [92.2\%]), Medicaid (643 [7.0\%]), and Medicare (72 [0.8\%]).

Each encounter recorded up to five presenting concerns, and 12,020 concerns were documented across all encounters (Table 2). Musculoskeletal concerns involving the back were the most frequent presenting concerns overall $(6,406$ [53.3\%]) and for each age group. The next most common concerns were lower extremity $(1,291$ [10.7\%]), neck (1,184 [9.9\%]), upper extremity $(1,175$ [9.8\%]), and hip/pelvic pain (862 [7.2\%]).

Excluding somatic dysfunction, there were 18,285 documented clinical assessments, of which 17,271 (94.4\%) were neuromusculoskeletal and 1,014 (5.6\%) were nonneuromusculoskeletal (Table 3). For neuromusculoskeletal assessments, the most frequent regions assessed were the thoracolumbar $(7,109$ [38.9\%]), cervical (3,299 [18.0\%]), lower extremity (1,923 [10.5\%]), and upper extremity (1,705 [9.3\%]) regions. For non-neuromusculoskeletal assessments, the most common organ systems assessed were neuropsychiatry (216 [1.2\%]); gastrointestinal (167 [0.9\%]); and ear, nose, and throat (165 [0.9\%]).

Corresponding with body regions treated with OMT, up to 10 somatic dysfunction body region assessments could be documented per encounter. Across all encounters, 46,100 somatic dysfunction assessments were documented, and the mean (SD) number of somatic dysfunction assessments per encounter was 5 (1.7) (Table 4). No difference was found in mean (SD) number of somatic dysfunctions per encounter between age groups ( $p=0.25)$ : 5.1 (1.8) for those aged 60-69 years, 5 (1.7) for those aged 70-79 years, 5.1 (1.7) for those aged 80-89 years, and 5 (1.7) for those aged 90 years and older. Across all age groups, the most common body region treated with OMT was the thoracic region $(7,263$ [79.3\% of all encounters and $15.8 \%$ of all somatic dysfunction assessments]).

Up to 19 different types of OMT techniques could be documented in the EHR per clinical encounter (Table 5). Cumulatively in 9,155 encounters, the total number of OMT techniques documented was 43,862 and the mean (SD) 
Table 2: Presenting concerns of geriatric patients from an outpatient osteopathic neuromusculoskeletal medicine clinic treated with osteopathic manipulative treatment by age groups $(\mathrm{N}=12,020)$.

\begin{tabular}{|c|c|c|c|c|c|}
\hline \multirow[t]{2}{*}{ Presenting concern $^{\mathrm{a}}$} & \multirow[t]{2}{*}{ Overall, n (\%) } & \multicolumn{4}{|c|}{ Concerns by age group, $\mathbf{n}(\%)$} \\
\hline & & $60-69$ years & $70-79$ years & $80-89$ years & $\geq 90$ years \\
\hline Back & $6,406(53.3)$ & $2,477(49.6)$ & $2,307(55.9)$ & $1,324(55.7)$ & $298(57.6)$ \\
\hline Lower extremity & $1,291(10.7)$ & $561(11.2)$ & $424(10.3)$ & $271(11.4)$ & $35(6.8)$ \\
\hline Neck & $1,184(9.9)$ & $523(10.5)$ & $378(9.2)$ & $215(9.0)$ & $68(13.2)$ \\
\hline Upper extremity & $1,175(9.8)$ & $513(10.3)$ & $425(10.3)$ & $189(8.0)$ & $48(9.3)$ \\
\hline Hip/pelvis & $862(7.2)$ & $357(7.2)$ & $271(6.6)$ & $192(8.1)$ & $42(8.1)$ \\
\hline Head & $337(2.8)$ & $200(4.0)$ & $85(2.1)$ & $45(1.9)$ & $7(1.4)$ \\
\hline Rib & $275(2.3)$ & $138(2.8)$ & $86(2.1)$ & $48(2.0)$ & $3(0.6)$ \\
\hline Musculoskeletal (nonspecific) & $21(0.2)$ & $14(0.3)$ & $2(0.1)$ & $5(0.2)$ & $0(0)$ \\
\hline Non-musculoskeletal & 469 (3.9) & $212(4.2)$ & $152(3.7)$ & $89(3.7)$ & $16(3.1)$ \\
\hline
\end{tabular}

${ }^{a}$ Each of the total 9,155 patient encounters could list up to five presenting concerns.

Table 3: Categories of clinical assessments of geriatric patients from an outpatient osteopathic neuromusculoskeletal medicine clinic treated with osteopathic manipulative treatment by age group $(\mathrm{N}=18,290)$.

\begin{tabular}{|c|c|c|c|c|c|}
\hline \multirow[t]{2}{*}{ Assessment categories } & \multirow[t]{2}{*}{ Assessments between categories ${ }^{\mathrm{a}}, \mathrm{n}(\%)$} & \multicolumn{4}{|c|}{ Assessments by age groups ${ }^{b}, \mathrm{n}(\%)$} \\
\hline & & $60-69$ years & $70-79$ years & $80-89$ years & $\geq 90$ years \\
\hline Neuromusculoskeletal & $17,271(94.5)$ & $6,995(40.5)$ & $5,916(34.3)$ & $3,515(20.4)$ & $845(4.9)$ \\
\hline Thoracolumbar region & 7,109 (38.9) & $2,708(38.1)$ & $2,560(36.0)$ & $1,511(21.3)$ & $330(4.6)$ \\
\hline Cervical region & $3,299(18.0)$ & $1,317(39.9)$ & $1,038(31.5)$ & $712(21.6)$ & $232(18.0)$ \\
\hline Lower extremity region & $1,923(10.5)$ & $813(42.3)$ & $658(34.2)$ & $406(21.1)$ & $46(2.4)$ \\
\hline Upper extremity region & $1,705(9.3)$ & $731(42.9)$ & $613(40.0)$ & $281(16.5)$ & $80(4.7)$ \\
\hline Hip/pelvis region & $1,238(6.8)$ & $518(41.8)$ & $389(31.4)$ & $254(20.5)$ & $77(6.2)$ \\
\hline Head region & $530(2.9)$ & $309(58.3)$ & $148(27.9)$ & $64(12.1)$ & $9(1.7)$ \\
\hline Rib/chest wall & $405(2.2)$ & $213(52.6)$ & $127(31.4)$ & $54(13.3)$ & $11(2.7)$ \\
\hline Abdomen & $11(0.1)$ & $7(63.6)$ & $4(36.4)$ & $0(0)$ & $0(0)$ \\
\hline Nonspecific/generalized & $1,051(5.8)$ & $379(36.1)$ & $379(36.1)$ & $233(22.2)$ & $60(5.7)$ \\
\hline Non-neuromusculoskeletal & $1,014(5.6)$ & $423(41.7)$ & $360(35.5)$ & $191(18.8)$ & $40(3.9)$ \\
\hline Neuropsychiatric & $216(1.2)$ & $63(29.2)$ & $94(43.5)$ & $54(25.0)$ & $5(2.3)$ \\
\hline Gastrointestinal & $167(0.9)$ & $76(45.5)$ & $40(24.0)$ & $38(22.8)$ & $13(7.8)$ \\
\hline Ear, nose, throat & $165(0.9)$ & $83(50.3)$ & $45(27.3)$ & $29(17.6)$ & $8(4.9)$ \\
\hline Other, uncategorized & $159(0.9)$ & $92(57.9)$ & $51(32.1)$ & $15(9.4)$ & $1(0.6)$ \\
\hline Pulmonary & $83(0.5)$ & $15(18.1)$ & $55(66.3)$ & $9(10.8)$ & $4(4.8)$ \\
\hline Integumentary & $41(0.2)$ & $15(36.6)$ & $13(31.7)$ & $10(24.4)$ & $3(7.3)$ \\
\hline Cardiac & $49(0.3)$ & $10(20.4)$ & $21(31.7)$ & $10(24.4)$ & $3(7.3)$ \\
\hline Hematology/oncology & $63(0.3)$ & $28(44.4)$ & $21(33.3)$ & $9(14.3)$ & $5(7.9)$ \\
\hline Genitourinary & $31(0.2)$ & $10(32.3)$ & $15(48.4)$ & $6(19.4)$ & $0(0)$ \\
\hline Endocrine & $40(0.2)$ & $31(77.5)$ & $5(12.5)$ & $4(10)$ & $0(0)$ \\
\hline
\end{tabular}

${ }^{a}$ Assessments between categories represents the percentage distribution of each assessment between all assessment categories.

${ }^{\mathrm{b}}$ Assessments by age groups represents the percentage distribution of each assessment category between the four age groups.

number of different types of techniques documented per encounter was 4.8 (1.8) (Table 5). The most frequently documented technique was muscle energy both overall $(7,203[16.4 \%])$ and for most age groups; myofascial release was most commonly used for those aged 90 years and older (270 [19.8\%]). In an analysis by age group, the use of HVLA decreased with increasing age group $(\mathrm{p}<0.001)$.

Overall treatment response was documented in 7,316 (79.9\%) of 9,155 encounters. Of encounters with a treatment response, 7,290 (99.6\%) were improved, $15(0.2 \%)$ were unchanged, $10(0.1 \%)$ were resolved, and one $(0.01 \%)$ was worse.

\section{Discussion}

As is the trend with the geriatric population of the United States [24], the current study found the percentage of 
Table 4: Documented somatic dysfunction assessments of geriatric patients from an outpatient osteopathic neuromusculoskeletal medicine clinic treated with osteopathic manipulative treatment by age group $(\mathrm{N}=46,100)$.

\begin{tabular}{|c|c|c|c|c|c|}
\hline \multirow[t]{2}{*}{ ICD-10 region (code) } & \multirow[t]{2}{*}{ Overall, n (\%) } & \multicolumn{4}{|c|}{ Somatic dysfunction assessments by age groups, $\mathrm{n}(\%)$} \\
\hline & & $60-69$ years $(n=21,104)$ & $70-79$ years $(n=14,582)$ & $80-89$ years $(n=9,005)$ & $\geq 90$ years $(n=1,409)$ \\
\hline Head (M99.00) & $3,878(8.4)$ & $1,973(9.3)$ & $1,047(7.2)$ & $720(8.0)$ & $138(9.8)$ \\
\hline Cervical (M99.01) & $6,327(13.7)$ & $2,948(14.0)$ & $1,967(13.5)$ & $1,191(13.2)$ & $221(15.7)$ \\
\hline Thoracic (M99.02) & $7,263(15.8)$ & $3,331(15.8)$ & $2,343(16.1)$ & $1,340(14.9)$ & $249(17.7)$ \\
\hline Lumbar (M99.03) & $6,487(14.1)$ & $2,801(13.3)$ & $2,175(14.9)$ & $1,336(14.8)$ & $175(12.4)$ \\
\hline Sacral (M99.04) & $4,774(10.4)$ & $1,996(9.5)$ & $1,647(11.3)$ & $1,029(11.4)$ & $102(7.2)$ \\
\hline Pelvic (M99.05) & $4,915(10.7)$ & $2,250(10.7)$ & $1,651(11.3)$ & $917(10.2)$ & $97(6.9)$ \\
\hline Lower extremity (M99.06) & $3,536(7.7)$ & $1,566(7.4)$ & $1,086(7.4)$ & $788(8.8)$ & $96(6.8)$ \\
\hline Upper extremity (M99.07) & $2,197(4.8)$ & $1,107(5.2)$ & $602(4.1)$ & $392(4.4)$ & $96(6.8)$ \\
\hline Rib (M99.08) & $6,123(13.3)$ & $2,839(13.5)$ & $1,905(13.1)$ & $1,160(12.9)$ & $219(15.5)$ \\
\hline Abdomen (M99.09) & $600(1.3)$ & $293(1.4)$ & $159(1.1)$ & $132(1.5)$ & $16(1.1)$ \\
\hline
\end{tabular}

ICD-10, International Classification of Diseases, Tenth Revision.

Table 5: Osteopathic manipulative treatment techniques used in the treatment of geriatric patients at an outpatient osteopathic neuromusculoskeletal medicine clinic $(\mathrm{N}=43,862)$.

\begin{tabular}{|c|c|c|c|c|c|}
\hline \multirow[t]{2}{*}{ Technique } & \multirow[t]{2}{*}{ Overall, n (\%) } & \multicolumn{4}{|c|}{ Age groups, n (\%) } \\
\hline & & $60-69$ years & $70-79$ years & $80-89$ years & $\geq 90$ years \\
\hline Muscle energy & $7,203(16.4)$ & $3,286(16.1)$ & $2,362(17.3)$ & $1,370(16.4)$ & $185(13.5)$ \\
\hline Myofascial release & $6,540(14.9)$ & $2,961(14.5)$ & $2,000(14.6)$ & $1,309(15.7)$ & $270(19.8)$ \\
\hline Articular & $6,023(13.7)$ & $2,674(13.1)$ & $1,942(14.2)$ & $1,235(14.8)$ & $172(12.6)$ \\
\hline Soft tissue & 4,687 (10.7) & $2,144(10.5)$ & $1,551(11.4)$ & $846(10.1)$ & $146(10.7)$ \\
\hline Still technique & $3,685(8.4)$ & $1,722(8.4)$ & $1,138(8.3)$ & $720(8.6)$ & $105(7.7)$ \\
\hline Percussion hammer & $3,163(7.2)$ & $1,278(6.2)$ & $1,062(7.8)$ & $703(8.4)$ & $120(8.8)$ \\
\hline Balanced ligamentous tension & $2,902(6.6)$ & $1,286(6.3)$ & $910(6.7)$ & $570(6.8)$ & $136(10.0)$ \\
\hline Counterstrain & $2,247(5.1)$ & $1,180(5.8)$ & $642(4.7)$ & $361(4.3)$ & $64(4.7)$ \\
\hline HVLA & $1,684(3.8)$ & $1,031(5.0)$ & $497(3.6)$ & $153(1.8)$ & $3(0.2)$ \\
\hline Cranial & $1,356(3.1)$ & $744(3.6)$ & $363(2.7)$ & $213(2.6)$ & $36(2.6)$ \\
\hline Ligamentous articular strain & $1,127(2.6)$ & $565(2.8)$ & $352(2.6)$ & $196(2.4)$ & $14(1.0)$ \\
\hline Facilitated positional release & $888(2.0)$ & $423(2.1)$ & 244 (1.8) & $173(2.1)$ & $48(3.5)$ \\
\hline Progressive neuromuscular inhibition & 840 (1.9) & $405(2.0)$ & $219(1.6)$ & $185(2.2)$ & $31(2.3)$ \\
\hline Functional & $457(1.0)$ & $227(1.1)$ & $114(0.8)$ & $103(1.2)$ & $13(1.0)$ \\
\hline Other & $429(1.0)$ & $219(1.1)$ & $114(0.8)$ & $90(1.1)$ & $6(0.4)$ \\
\hline Visceral manipulation & $289(0.7)$ & $149(0.7)$ & $65(0.5)$ & $66(0.8)$ & $9(0.7)$ \\
\hline Neurofascial release & $160(0.4)$ & $78(0.4)$ & $48(0.4)$ & $29(0.4)$ & $5(0.4)$ \\
\hline Lymphatic & $113(0.3)$ & $63(0.3)$ & $25(0.2)$ & $22(0.3)$ & $3(0.2)$ \\
\hline Integrated neuromuscular release & $69(0.2)$ & $39(0.2)$ & $17(0.1)$ & $13(0.2)$ & $0(0)$ \\
\hline
\end{tabular}

HVLA, high-velocity, low-amplitude.

geriatric patients in each age group decreased with increasing age and the majority of patients in each age group were women. We also found a gradual but significant increase in the number of encounters per year with increasing age decade and that women had a higher mean number of encounters per year than men in all age groups. This finding is consistent with existing data showing that healthcare costs [25-27] and utilization [26, 27] increase with increasing age and that women tend to have higher utilization of healthcare than men [25-27].
Geriatric patients commonly present to our outpatient ONMM clinic with acute and chronic pain symptoms; somatic dysfunction that may be contributing to the patient's specific symptoms is typically found on physical examination. As such, OMT is provided using a variety of techniques that are directed toward the specific physical findings, and patients commonly report improvement after treatment at the time of the visit. Our results showed that OMM was predominately used at our clinic as part of the management of neuromusculoskeletal concerns and 
conditions. Back pain was the most common presenting concern for all age groups, and thoracolumbar conditions were most frequently assessed. This finding is consistent with low back pain as a common condition and as the global leading cause of years lived with disability [28]. The incidence of low back pain peaks at 80-89 years and then begins to decline in those aged 90 years and older [28].

Neuromusculoskeletal conditions of the cervical region were the second most frequent type of assessment in geriatric patients treated with OMT in our current study. In previous studies $[29,30]$, neck pain was more common among individuals aged 60 years and older than in younger individuals. Neck pain in the elderly population is associated with degenerative changes in the cervical spine and with osteoporosis [31]. Further, OMT has been shown as a cost-effective approach that can provide benefit to adults with back and neck pain [32-37]. Studies have also shown that OMT improves low back pain and quality of life in older patients [19-21]. However, a search of the literature revealed a deficit of studies investigating the use of OMT for neck pain, specifically in geriatric patients, which highlights a need for additional study in this area.

Other frequently documented concerns in our study included lower extremity, upper extremity, and hip/pelvis pain. Our patients' common concerns and conditions are consistent with results from a previous meta-analysis that found back and lower extremity pain were prevalent in older people and were correlated with increasing incidence of osteoarthritic conditions as people age [38]. In a survey of 44.8 million people aged 65 and older, $49.6 \%$ reported at least one doctor-diagnosed arthritic condition [39]. Women represented a larger proportion of our patient population and encounters. This finding is consistent with a higher prevalence of age-adjusted, arthritis-attributable activity limitations in women [39].

Non-neuromusculoskeletal assessments accounted for $5.6 \%$ of documented assessments in our results. Of these, the most frequent were neuropsychiatric assessments (1.2\%), including dizziness, hemiplegia, and tremor. The next most frequent non-neuromusculoskeletal assessments were gastrointestinal (0.9\%), including acute gastritis, gastroesophageal reflux, abdominal pain, and constipation; and ear, nose, and throat assessments (0.9\%), including sinusitis, upper respiratory tract infection, and tinnitus. Because somatic dysfunction is the clinical indication for OMT, many of these conditions may be underreported as assessments. For example, treatment of the abdomen was reported in 600 encounters and the use of visceral manipulation was reported in 289 encounters, but gastrointestinal assessments were included in only 167 encounters. Future studies should investigate review of systems, past medical history, and free-text narratives to determine how often OMM is provided as adjunctive treatment of nonneuromusculoskeletal concerns. Given the large evidence base of manual therapies for conditions such as constipation [40-44], the documentation and use of OMM for non-neuromusculoskeletal conditions may be an appropriate topic for continuing medical education. Our findings prompted in-service training for physicians at the institution of the current study aimed to ensure more comprehensive encounter documentation.

The most frequently used OMT technique in the current study was muscle energy, except in patients aged 90 years and older, where myofascial release was used more often. The types of OMT techniques used in our study are similar to reported OMT use among practicing osteopathic physicians and students taking the Comprehensive Osteopathic Medical Licensing Examination of the United States Performance Evaluation [2, 19, 45]. In a recent study of 10,150 OMM practice treatments performed by third-year and fourth-year osteopathic medical students [46], patients aged 60 years and older accounted for approximately $14 \%$ of the OMT documented by the students, and muscle energy was the most commonly used. These findings suggest OMT training provided in osteopathic medical schools is consistent with OMT use patterns by practicing osteopathic physicians $[1,2,45]$ and, therefore, is appropriate preparation for the clinical integration of OMM into the management of common geriatric conditions.

In our study, HVLA techniques accounted for only $3.8 \%$ of all OMT techniques used and progressively declined from $5 \%$ in the $60-69$ age group to $0.2 \%$ in the 90 years and older group. This finding, along with reduced use of muscle energy in the $>90$ age group, likely reflects the tendency to use more indirect and gentle techniques with older patients. Further, HVLA and other direct techniques are relatively contraindicated in the presence of conditions associated with musculoskeletal fragility, such as osteoporosis, where prevalence increases with advancing age [47, 48]. Our results are also consistent with those from a survey-based study by Channel et al. of 197 physicians specializing in ONMM [1], which found lower utilization of rate of HVLA in geriatric patients.

Of the encounters in our study with a documented treatment response, $99.6 \%$ reported improvement with less than $0.2 \%$ reporting unchanged or worse symptoms. The reported improvement in our results was greater than the $92 \%$ of encounters reporting improvement from a practicebased research network study of 2,569 encounters involving OMT in adults aged $18-93$ years [49]. The immediate benefit of manual therapies has been well documented. For instance, manual therapies have been shown to increase 
soft tissue pressure pain thresholds, resulting in immediate pain reduction [50-53]. A systematic review [54] found evidence that geriatric patients may be more sensitive to mechanically evoked pain than younger patients, which suggests older patients may be more likely to experience an immediate benefit from OMT. The annual direct medical cost of arthritis is $\$ 81$ billion in the United States [39]. Nearly $80 \%$ of patients in the current study had Medicare as their primary insurance. If OMM can provide cost-effective, adjunctive treatment of arthritis conditions in older patients with minimal treatment-associated morbidity and mortality, then long-term studies of the cost, outcomes, and potential contraindications of OMM are justified and should be prioritized in research funding.

The primary limitation of the current study was that our data was from a single specialty ONMM clinic, which may limit the generalizability of the findings to other specialties and ONMM clinics. Another limitation was the exclusion of data from free-text narratives in the EHR encounters notes. The free-text narratives typically describe quality of life information, fall histories, and medication and lifestyle interventions; they may also include information about patient symptoms that were not documented as presenting concerns or clinical assessments. Inclusion of that information may have better described treatment plans for non-neuromusculoskeletal conditions and outcomes in our patient population.

\section{Conclusions}

The current study investigated the presentation and management of geriatric patients receiving OMT at an outpatient ONMM clinic. Our results indicated that geriatric patients primarily presented with musculoskeletal concerns common for their age group, such as back, neck, and lower extremity concerns. Future studies are needed to determine whether these findings are generalizable to OMM provided by other ONMM clinics or by other specialty provider types. Given the reported immediate improvement in presenting symptoms after OMM in our patient population, longitudinal studies should be conducted to determine the length of time the improvement persists and the overall health impact to the patients receiving OMM. Our findings also identified common musculoskeletal concerns and conditions with a sufficient incidence for the pursuit of future prospective, randomized studies focusing on long-term outcomes, such as quality of life and fall risk reduction, as well as contraindications. Results from such studies could be used to establish treatment guidelines for geriatric patients with musculoskeletal pain. Given the high prevalence of musculoskeletal concerns in the geriatric population, clinicians should consider including $\mathrm{OMM}$ as part of the management of pain conditions in this population.

Acknowledgments: The authors thank Toni Matticks, clinical business analyst at A.T. Still University, for her assistance with extracting the electronic health record data. We also thank Deborah Goggin, MA, ELS, scientific writer from the Department of Research Support at A.T. Still University, for her editorial assistance.

Research funding: None reported.

Author contributions: All authors provided substantial contributions to conception and design, acquisition of data, or analysis and interpretation of data; all authors drafted the article or revised it critically for important intellectual content; all authors gave final approval of the version of the article to be published; and all authors agree to be accountable for all aspects of the work in ensuring that questions related to the accuracy or integrity of any part of the work are appropriately investigated and resolved.

Competing interests: Authors state no conflict of interest. Informed consent: This retrospective chart review required no informed consent from patients.

Ethical approval: This study was deemed exempt by the institutional review board at A.T. Still University Kirksville.

\section{References}

1. Channell MK, Wang Y, McLaughlin MH, Ciesielski J, Pomerantz SC. Osteopathic manipulative treatment for older patients: a national survey of osteopathic physicians. J Am Osteopath Assoc 2016;116: 136-43.

2. Johnson SM, Kurtz ME. Conditions and diagnoses for which osteopathic primary care physicians and specialists use osteopathic manipulative treatment. J Am Osteopath Assoc 2002;102:52732-537-40.

3. Shapiro E. The physician visit patterns of chiropractic users: health-seeking behavior of the elderly in Manitoba, Canada. Am J Publ Health 1983;73:553-7.

4. Baran A, Ates S. The effects of abdominal massage in the management of constipation in elderly people: a randomized controlled study. Top Geriatr Rehabil 2019;35:134-40.

5. Forte ML, Maiers M. Functional limitations in adults who utilize chiropractic or osteopathic manipulation in the United States: analysis of the 2012 National Health Interview Survey. J Manipulative Physiol Ther 2017;40:668-75.

6. Kendall JC, Hartvigsen J, French SD, Azari MF. Is there a role for neck manipulation in elderly falls prevention? An overview. J Can Chiropr Assoc 2015;59:53-63.

7. Knebl JA, Shores JH, Gamber RG, Gray WT, Herron KM. Improving functional ability in the elderly via the Spencer technique, an osteopathic manipulative treatment: a randomized, controlled trial. J Am Osteopath Assoc 2002;102:387-96. 
8. Lee SH, Kim JY, Yeo S, Kim SH, Lim S. Meta-analysis of massage therapy on cancer pain. Integr Cancer Ther 2015;14: 297-304.

9. Muller T, Pietsch A. Comparison of gait training versus cranial osteopathy in patients with Parkinson's disease: a pilot study. NeuroRehabilitation 2013;32:135-40.

10. Noll DR, Degenhardt BF, Johnson JC. Multicenter Osteopathic Pneumonia Study in the Elderly: subgroup analysis on hospital length of stay, ventilator-dependent respiratory failure rate, and in-hospital mortality rate. J Am Osteopath Assoc 2016;116: 574-87.

11. Oliver M. Effectiveness of foot massage on improving the balance among elderly in a selected destitute home, Mangalore. Indian J Gerontol 2017;31:444-55.

12. Pellerin F, Papin-Richard E, Guiheneuc P, Niel S, Guihard G. Can osteopathic manipulative treatment modify the posture in elderly people? A single-case study. J Bodyw Mov Ther 2015;19: 380-8.

13. Rivera-Martinez S, Wells MR, Capobianco JD. A retrospective study of cranial strain patterns in patients with idiopathic Parkinson's disease. J Am Osteopath Assoc 2002;102:417-22.

14. Snider KT, Snider EJ, Johnson JC, Hagan C, Schoenwald C. Preventative osteopathic manipulative treatment and the elderly nursing home resident: a pilot study. J Am Osteopath Assoc 2012; 112:489-501.

15. Cinar S, Eser I, Khorshid L. The effects of back massage on the vital signs and anxiety level of elderly staying a rest home. Hacettepe Univ Fac Health Sci Nurs J 2009;16:14-21.

16. Harris M, Richards KC. The physiological and psychological effects of slow-stroke back massage and hand massage on relaxation in older people. J Clin Nurs 2010;19:917-26.

17. Mok E, Woo CP. The effects of slow-stroke back massage on anxiety and shoulder pain in elderly stroke patients. Complement Ther Nurs Midwifery 2004;10:209-16.

18. Rapaport MH, Schettler P, Breese C. A preliminary study of the effects of a single session of Swedish massage on hypothalamicpituitary-adrenal and immune function in normal individuals. J Altern Complement Med 2010;16:1079-88.

19. Arienti C, Bosisio T, Ratti S, Miglioli R, Negrini S. Osteopathic manipulative treatment effect on pain relief and quality of life in oncology geriatric patients: a nonrandomized controlled clinical trial. Integr Cancer Ther 2018;17:1163-71.

20. dos Santos PO, Cader SA, de Mello DB, Mendonca de Sousa MJ, da Silva Coelho E, Dantas EHM. Quality of life in aged with low back pain treated with osteopathy. Ter Man 2011;9:805-11.

21. Povoa LC, Vanuzzi FK, Antunes Ferreira AP, de Sa Ferreira A. Osteopathic intervention in the elderly and its impact on quality of life. Fisioter Mov 2011;24:429-36.

22. Snider KT, Jorgensen DJ. Billing and coding for osteopathic manipulative treatment. J Am Osteopath Assoc 2009;109: 409-13.

23. American Academy of Professional Coders. ICD-10 CM expert 2019. Salt Lake City, UT: American Academy of Professional Coders; 2018.

24. United States Census Bureau. National population by characteristics: 2010-2019. United States Census Bureau website. Available from: https://www.census.gov/data/tables/ time-series/demo/popest/2010s-national-detail.html [Accessed 31 Jul 2020].
25. Dieleman JL, Baral R, Birger M, Bui AL, Bulchis A, Chapin A, et al. US spending on personal health care and public health. J Am Med Assoc 2016;316:2627-46.

26. Kalseth J, Halvorsen T. Health and care service utilisation and cost over the life-span: a descriptive analysis of population data. BMC Health Serv Res 2020;20:435.

27. Wammes JJG, van der Wees PJ, Tanke MAC, Westert GP, Jeurissen PPT. Systematic review of high-cost patients' characteristics and healthcare utilisation. BMJ Open 2018;8:e023113.

28. Wu A, March L, Zheng X, Huang J, Wang X, Zhao J, et al. Global low back pain prevalence and years lived with disability from 1990 to 2017: estimates from the Global Burden of Disease Study 2017. Ann Transl Med 2020;8:299.

29. Fejer R, Kyvik KO, Hartvigsen J. The prevalence of neck pain in the world population: a systematic critical review of the literature. Eur Spine J 2006;15:834-48.

30. Genebra C, Maciel NM, Bento TPF, Simeao S, Vitta A. Prevalence and factors associated with neck pain: a population-based study. Braz J Phys Ther 2017;21:274-80.

31. Wang XR, Kwok TCY, Griffith JF, Man Yu BW, Leung JCS, Wang YXJ. Prevalence of cervical spine degenerative changes in elderly population and its weak association with aging, neck pain, and osteoporosis. Ann Transl Med 2019;7:486.

32. Cruser dA, Maurer D, Hensel K, Brown SK, White K, Stoll ST. A randomized, controlled trial of osteopathic manipulative treatment for acute low back pain in active duty military personnel. J Man Manip Ther 2012;20:5-15.

33. Franke H, Franke JD, Fryer G. Osteopathic manipulative treatment for nonspecific low back pain: a systematic review and metaanalysis. BMC Musculoskelet Disord 2014;15:286.

34. Franke H, Franke JD, Fryer G. Osteopathic manipulative treatment for chronic nonspecific neck pain: a systematic review and metaanalysis. Int J Osteopath Med 2015;18:255-67.

35. Licciardone JC, Brimhall AK, King LN. Osteopathic manipulative treatment for low back pain: a systematic review and metaanalysis of randomized controlled trials. BMC Musculoskelet Disord 2005;6:43.

36. Task Force on the Low Back Pain Clinical Practice Guidelines. American Osteopathic Association guidelines for osteopathic manipulative treatment (OMT) for patients with low back pain. J Am Osteopath Assoc 2016;116:536-49.

37. Verhaeghe N, Schepers J, van Dun P, Annemans L. Osteopathic care for low back pain and neck pain: a cost-utility analysis. Complement Ther Med 2018;40:207-13.

38. Abdulla A, Adams N, Bone M, Elliott AM, Gaffin J, Jones D. Guidance on the management of pain in older people. Age Ageing 2013;42(1 Suppl):i1-57.

39. Barbour KE, Helmick CG, Boring M, Brady TJ. Vital signs: prevalence of doctor-diagnosed arthritis and arthritisattributable activity limitation: United States, 2013-2015. MMWR Morb Mortal Wkly Rep 2017;66:246-53.

40. Angus K, Asgharifar S, Gleberzon B. What effect does chiropractic treatment have on gastrointestinal (Gl) disorders: a narrative review of the literature. J Can Chiropr Assoc 2015;59:122-33.

41. Bromley D. Abdominal massage in the management of chronic constipation for children with disability. Community Pract 2014; 87:25-9.

42. Cohen-Lewe A. Osteopathic manipulative treatment for colonic inertia. J Am Osteopath Assoc 2013;113:216-20. 
43. Gursen C, Kerem Gunel M, Kaya S, Kav T, Akbayrak T. Effect of connective tissue manipulation on symptoms and quality of life in patients with chronic constipation: a randomized controlled trial. J Manipulative Physiol Ther 2015;38:335-43.

44. Sinclair $M$. The use of abdominal massage to treat chronic constipation. J Bodyw Mov Ther 2011;15:436-45.

45. Langenau EE, Dowling DJ, Dyer C, Roberts WL. Frequency of specific osteopathic manipulative treatment modalities used by candidates while taking COMLEX-USA Level 2-PE. J Am Osteopath Assoc 2012;112:509-13.

46. Snider KT, Couch R, Bhatia S. Osteopathic manipulative medicine practice patterns of third-year and fourth-year osteopathic medical students: an educational research project. J Am Osteopath Assoc 2020;120:293-302.

47. Kuchera ML, Seffinger MA, Boesler D, Connett DA. Effectiveness and safety of osteopathic manipulative treatment. In: Seffinger MA, editor. Foundations of osteopathic medicine: philosophy, science, clinical applications, and research, 4th ed. Philadelphia, PA: Wolters Kluwer; 2018:1531-42 pp.

48. Milte R, Crotty M. Musculoskeletal health, frailty and functional decline. Best Pract Res Clin Rheumatol 2014;28:395-410.

49. Degenhardt BF, Johnson JC, Gross SR, Hagan C, Lund G, Curry WJ. Preliminary findings on the use of osteopathic manipulative treatment: outcomes during the formation of the practice-based research network, DO-Touch.NET. J Am Osteopath Assoc 2014; 114:154-70.

50. Coronado RA, Gay CW, Bialosky JE, Carnaby GD, Bishop MD, George SZ. Changes in pain sensitivity following spinal manipulation: a systematic review and meta-analysis. J Electromyogr Kinesiol 2012;22:752-67.

51. Hanney WJ, Peuntedura EJ, Kolber MJ, Liu X, Pabian PS, Cheatham SW. The immediate effects of manual stretching and cervicothoracic junction manipulation on cervical range of motion and upper trapezius pressure pain thresholds. J Back Musculoskelet Rehabil 2017;30:1005-13.

52. Savva C, Giakas G, Efstathiou M. The role of the descending inhibitory pain mechanism in musculoskeletal pain following high-velocity, low amplitude thrust manipulation: a review of the literature. J Back Musculoskelet Rehabil 2014;27:377-82.

53. Voogt L, de Vries J, Meeus M, Struyf F, Meuffels D, Nijs J. Analgesic effects of manual therapy in patients with musculoskeletal pain: a systematic review. Man Ther 2015;20: 250-6.

54. El Tumi H, Johnson MI, Dantas PBF, Maynard MJ, Tashani OA. Age-related changes in pain sensitivity in healthy humans: a systematic review with meta-analysis. Eur J Pain 2017;21: 955-64. 